\title{
Suicide for the Purpose of Gaining Insurance Payouts in Japan
}

\author{
Toyohiko Kodama1, Hirokazu Fujimoto², Yuko Tamura', Mika Kataoka1 \\ ${ }^{1}$ Mie University Graduate School of Medicine, Mie, Japan \\ ${ }^{2}$ Kobe University Graduate School of Health Sciences, Kobe, Japan \\ Email: t-kodama@nurse.medic.mie-u.ac.jp
}

How to cite this paper: Kodama, T., Fujimoto, H., Tamura, Y. and Kataoka, M. (2017) Suicide for the Purpose of Gaining Insurance Payouts in Japan. Open Journal of Social Sciences, 5, 189-197. https://doi.org/10.4236/jss.2017.511014

Received: October 31, 2017

Accepted: November 27, 2017

Published: November 30, 2017

Copyright $\odot 2017$ by authors and Scientific Research Publishing Inc. This work is licensed under the Creative Commons Attribution-NonCommercial International License (CC BY-NC 4.0).

http://creativecommons.org/licenses/by-nc/4.0/

\begin{abstract}
Purpose: Studies on suicide for the purpose of gaining insurance payouts are rare globally; analyses of this phenomenon can help us understand it better and achieve more individualized care and support. Method: We used suicide data for the period from 2007 to 2015 from the "Summary Document Concerned with Suicide" released by the Japanese National Police Agency. We organized data on suicide committed to gain insurance payouts according to sex, age group, and year. We compared the sex ratio between these cases and the total cases of suicide using the Mann-Whitney U-test. We looked for correlations between this reason for suicide and other causes and factors in males. Results: Most people who committed suicide for the purpose of gaining insurance payouts were found to be in the 40 s to 60 s age group. The mean (SD) sex ratio (male/female) of these cases was 10.67 (2.36), significantly higher than the sex ratio for the total cases of suicide $(2.31(0.12))(p<0.001)$. The causes and factors that significantly correlated with suicide for insurance money from suicide were bankruptcy, business slump, multiple debts, debt because of consigner, other debts, and stress from debt collection. Conclusion: Males are at a greater risk for suicide for the purpose of gaining insurance payouts in Japan, and among them especially those in their 40 s to 60 s. The cause appears to be associated with debt. To develop more effective prevention measures for this kind of suicide, further studies are required.
\end{abstract}

\section{Keywords}

Suicide, Life Insurance, Sex Ratio, Age Group, Mental Health

\section{Introduction}

Suicide is a public health issue that affects communities, regions, and entire 
countries. Every year, more than 800,000 people commit suicide-one every 40 seconds [1]. Moreover, suicide has serious impacts on family, friends, and colleagues of the person who commits it. Nevertheless, suicide is a preventable public health problem. Understanding the causes of suicide - that are multiple-will help us find methods to prevent it.

Japan's suicide rate is the second highest among the countries of the Organisation for Economic Co-operation and Development (OECD) [2]. It increased considerably following the 1998 economic recession [3]; beginning in 1998, the number of suicides in Japan exceeded 30,000 per year for 14 consecutive years [3]. Although the suicide rate in Japan has been decreasing in recent years [3], it remains high among developed countries. Japan's National Police Agency releases the causes of and factors affecting suicides in the "Summary Document Concerned with Suicide" it compiles every year, based on evidence from suicide notes, Internet activity and e-mail communications, and other behavior; causes are determined for about $70 \%-75 \%$ of the total cases every year. Up to three causes/factors have been recorded for each case since 2007 (and one before that). Additionally, the causes and factors are grouped by type. Until 2006, they were classified into health issues, economic and livelihood issues, family issues, workrelated issues, love affairs, school-related issues, other, and unknown; since 2007, they have been divided at a more fine-grained level: for example, work-related issues are divided into career failure, personal relationship at work, change in the work environment, work-related fatigue, and other. Economic and livelihood issues are divided into 11 groups, one of which is insurance money from suicide; over 100 people who committed suicide have been placed in this category in recent years (2007-2010) [4] [5] [6] [7]. Previous studies have discussed suicide from multiple perspectives: mental illness, poverty, unemployment, personal relationships, drugs, and so on [8] [9] [10] [11]; however, statistics on suicide to gain an insurance payout are rare, and, to our knowledge, no studies have reported on this phenomenon in detail in the Japanese context. Therefore, factors influencing suicide to gain an insurance payout and its measures are not clear.

Suicide is a complex and multifaceted problem, and causes and factors for suicide vary considerably by individual. Thus, for suicide prevention, it is important to provide individualized care and support, which can be achieved through an analysis of suicide committed for the purpose of gaining insurance payouts, as it will improve our understanding of this understudied group.

\section{Data Collection and Analysis}

We analyzed data on suicides in Japan for the period 2007 to 2015 from the "Summary Document Concerned with Suicide" released by the National Police Agency. The Summary Document Concerned with Suicide is a compilation of the diverse suicide data from across Japan. Since 2007, the Summary Document Concerned with Suicide has reported detailed causes and factors for suicide, as discussed above. We broke down data on suicides for one factor, cited as to gain insurance payouts, according to sex, age group, and year. We also examined 
average the life insurance death benefits in each age group using data from a national survey of life insurance [12]. Using the Mann-Whitney U-test, we calculated the proportion of people in their $40 \mathrm{~s}$ to $60 \mathrm{~s}$ and the sex ratio for the cases of suicide committed for gaining insurance payouts in relation to the total cases of suicide. Suicide for gaining insurance payouts is one of the 11 causes and factors in the Summary Document Concerned with Suicide economic and livelihood issues category-namely, bankruptcy, business slump, unemployment, failure to get a job, hardship of life, multiple debts, joint guarantee debt, other debt, stress from debt collection, insurance money from suicide, and other; it was inferred that suicide for the purpose of gaining insurance payouts is strongly associated with these other causes and factors. We examined these causes and factors in males in order to determine their correlations with suicide committed for gaining insurance payouts. Data were analyzed using SPSS version 22 for Windows. All the data used in this study were previously published, and none of the data reveals the identity of the individuals; thus, no institutional review board clearance was required.

\section{Results}

Table 1 shows the sociodemographic characteristics of suicide for gaining insurance payouts in Japan. The largest number of such cases was 151, in 2007, and the smallest was 65 , in 2012; the numbers ranged between $0.32 \%$ and $0.65 \%$ of all suicides in Japan in their given years. (The percentage of the total number of cases for which causes or factors were identified was between $70.1 \%$ and $74.8 \%$ of the total.) In males, the age group most widely represented was the $50 \mathrm{~s}$ over the entire period studied, and the death benefit of males was larger than that of females in all age groups. It was largest in the $40 \mathrm{~s}$, followed by the $50 \mathrm{~s}$, and then the $30 \mathrm{~s}$. (Figure 1 shows the life insurance death benefit for each age

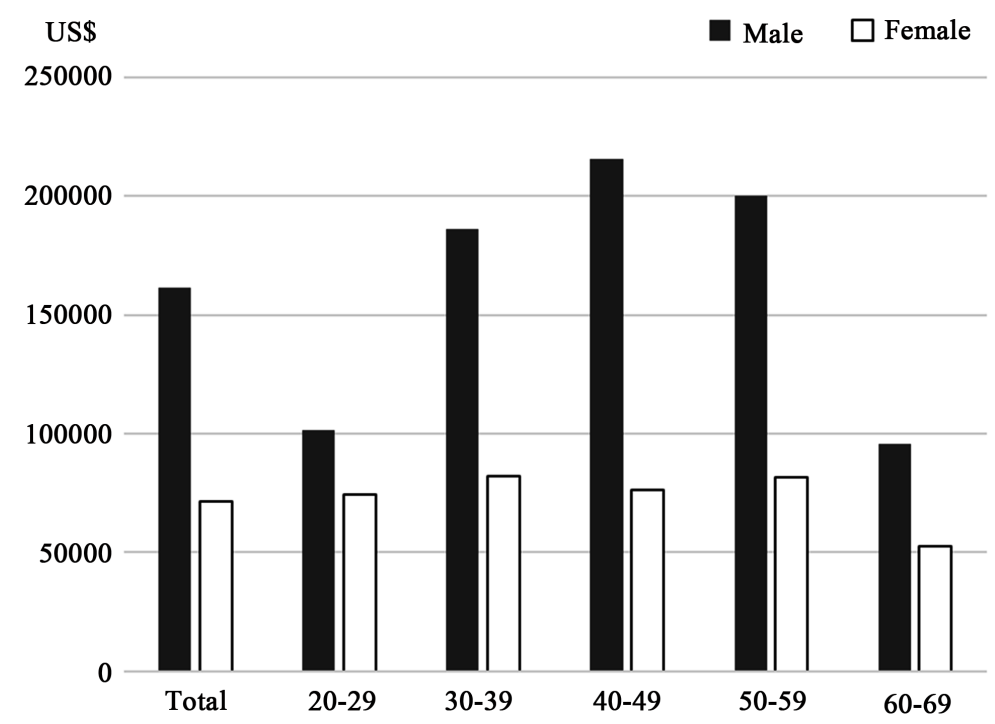

Figure 1. Average death benefit in each age group. Source: Japan institute of life insurance "Survey on life security 2016." 
Table 1. Sociodemographic characteristics of suicide for gaining insurance payouts (category: "Insurance money from suicide").

\begin{tabular}{|c|c|c|c|c|c|c|c|c|c|c|c|}
\hline & $\begin{array}{l}\text { Age } \\
\text { group }\end{array}$ & $\begin{array}{c}\text { Total } \\
\text { number } \\
\text { of cases }\end{array}$ & $\begin{array}{c}\text { Cases with } \\
\text { identified } \\
\text { causes }\end{array}$ & $20-29$ & $30-39$ & $40-49$ & $50-59$ & $60-69$ & $70+$ & Total & $\%$ \\
\hline \multirow[t]{3}{*}{2015} & Total & 24,025 & 17,981 & 1 & 4 & 21 & 25 & 15 & 4 & 70 & 0.39 \\
\hline & Male & 16,681 & & 1 & 4 & 20 & 24 & 14 & 2 & 65 & \\
\hline & Female & 7344 & & & & 1 & 1 & 1 & 2 & 5 & \\
\hline \multirow[t]{3}{*}{2014} & Total & 25,427 & 19,025 & 1 & 3 & 20 & 31 & 21 & 6 & 82 & 0.43 \\
\hline & Male & 17,386 & & 1 & 3 & 19 & 26 & 20 & 5 & 74 & \\
\hline & Female & 8041 & & & & 1 & 5 & 1 & 1 & 8 & \\
\hline \multirow[t]{3}{*}{2013} & Total & 27,283 & 20,256 & & 5 & 19 & 27 & 17 & 1 & 69 & 0.34 \\
\hline & Male & 18,787 & & & 5 & 16 & 24 & 15 & & 60 & \\
\hline & Female & 8496 & & & & 3 & 3 & 2 & 1 & 9 & \\
\hline \multirow[t]{3}{*}{2012} & Total & 27,858 & 20,615 & 1 & 2 & 17 & 20 & 20 & 5 & 65 & 0.32 \\
\hline & Male & 19,273 & & 1 & 1 & 17 & 19 & 17 & 5 & 60 & \\
\hline & Female & 8585 & & & 1 & & 1 & 3 & & 5 & \\
\hline \multirow[t]{3}{*}{2011} & Total & 30,651 & 22,581 & 1 & 7 & 16 & 40 & 29 & 2 & 95 & 0.42 \\
\hline & Male & 20,955 & & 1 & 7 & 13 & 37 & 27 & 1 & 86 & \\
\hline & Female & 9696 & & & & 3 & 3 & 2 & 1 & 9 & \\
\hline \multirow[t]{3}{*}{2010} & Total & 31,690 & 23,572 & 1 & 9 & 34 & 62 & 36 & 1 & 143 & 0.61 \\
\hline & Male & 22,283 & & 1 & 8 & 32 & 55 & 35 & 1 & 132 & \\
\hline & Female & 9407 & & & 1 & 2 & 7 & 1 & & 11 & \\
\hline \multirow[t]{3}{*}{2009} & Total & 32,845 & 24,434 & 1 & 9 & 32 & 57 & 28 & 9 & 136 & 0.56 \\
\hline & Male & 23,472 & & 1 & 9 & 28 & 53 & 25 & 5 & 121 & \\
\hline & Female & 9373 & & & & 4 & 4 & 3 & 4 & 15 & \\
\hline \multirow[t]{3}{*}{2008} & Total & 32,249 & 23,490 & 1 & 10 & 36 & 48 & 33 & 4 & 132 & 0.56 \\
\hline & Male & 22,831 & & 1 & 7 & 33 & 47 & 32 & 3 & 123 & \\
\hline & Female & 9418 & & & 3 & 3 & 1 & 1 & 1 & 9 & \\
\hline \multirow[t]{3}{*}{2007} & Total & 33,093 & 23,209 & 0 & 13 & 38 & 67 & 33 & 0 & 151 & 0.65 \\
\hline & Male & 23,478 & & & 12 & 36 & 62 & 29 & & 139 & \\
\hline & Female & 9615 & & & 1 & 2 & 5 & 4 & & 12 & \\
\hline
\end{tabular}

Source: National police agency (Japan), "Summary Document Concerned with Suicide”.

group.) The mean (SD) proportion of people who committed suicide for this reason and were in their 40 s to 60 s was $89.1 \%$ (2.18), significantly higher than the proportion of people in this age group who committed suicide in relation to the total number of suicide cases, which was $54.2 \%(7.32)(p<0.001)$ (Table 2). The number of males who committed suicide to gain an insurance payout was larger than the number of females each year; specifically, the mean (SD) sex ratio (male/female) of suicide for the purpose of gaining insurance payouts was 10.67 
Table 2. Characteristics of suicide for gaining insurance payout compared to total number of suicides, 2007-2015.

\begin{tabular}{cccc}
\hline & $\begin{array}{c}\text { Insurance money } \\
\text { from suicide }\end{array}$ & $\begin{array}{c}\text { Total } \\
\text { number }\end{array}$ & $p$ \\
\hline $\begin{array}{c}\text { Mean }(S D) \text { proportion of people who commit } \\
\text { suicide for insurance payout who are in their } 40 \mathrm{~s} \text { to } 60 \mathrm{~s}\end{array}$ & $89.1(2.18) \%$ & $54.2(7.32) \%$ & $0.000^{*}$ \\
Mean $(S D)$ sex ratio & $10.67(2.36)$ & $2.31(0.12)$ & $0.000^{*}$ \\
\hline
\end{tabular}

Mann-Whitney U-test. ${ }^{\star} p<0.001$.

(2.36), significantly higher than that for the total number of cases $(2.31(0.12))(p$ $<0.001$ ) (Table 2). Table 3 shows the correlation coefficients between the number of suicides for gaining insurance payouts and the number of suicides due to various other economic and livelihood causes and factors in males. The causes and factors found to be significantly correlated with suicide for gaining insurance payouts were bankruptcy, business slump, multiple debts, debt because of consigner, other debt, and stress from debt collection.

\section{Discussion}

Previous study results have shown that the proportion of suicides in Japan for the gaining insurance payouts is less than $1 \%$ in any year (Table 1 ). Although this proportion is low, it is not negligible, adding up to dozens of people each year. In addition, there is a possibility that the true number is undercounted, as suicidal persons trying to gain insurance payouts will not be inclined to mention that fact in a suicide note; neither are they likely to reveal this to anyone, or leave behind other evidence in general.

Our study's results revealed certain characteristics in the suicides that were committed for gaining insurance payouts. First, the data showed that the majority of people who commit suicide for this reason are in their $40 \mathrm{~s}$ to $60 \mathrm{~s}$. Although people in this age group account for $54.2 \%$ of all suicides, they account for $89.1 \%$ of suicides for gaining insurance payouts (Table 2). This might be influenced by the fact that many in these age groups are married and have families, and that the death benefit in the $70 \mathrm{~s}$ is lower than that for other age groups (Figure 1). More noteworthy is the sex ratio; a significantly greater proportion of cases of suicide for gaining insurance payouts were male. Often, as is the case in many countries, in Japan, the male is the family's principal breadwinner, and male death benefits are larger than those of females [13] (Figure 1), seemingly in order to offset the increased risk to family livelihood in the event of their death. Accordingly, many Japanese males may be strongly motivated by the belief that they are responsible for supporting the household financially [14]. If the male in the family, who is the principal breadwinner, dies, naturally, his household will fall into economic difficulties. Male breadwinners may strongly feel that they do not want to leave their bereaved in economic difficulties after their suicide; thus, they may try to secure a death benefit for them. 
Table 3. Correlation coefficient between number of suicides for gaining insurance payouts and number of suicides due to other causes in males (2007-2015).

\begin{tabular}{ccccccccccc}
\hline & Bankruptcy & $\begin{array}{c}\text { Business } \\
\text { slump }\end{array}$ & Unemployment & $\begin{array}{c}\text { Failure to } \\
\text { get job }\end{array}$ & $\begin{array}{c}\text { Hardship } \\
\text { of life }\end{array}$ & $\begin{array}{c}\text { Multiple } \\
\text { debts }\end{array}$ & $\begin{array}{c}\text { Joint } \\
\text { guarantee debt }\end{array}$ & $\begin{array}{c}\text { Other } \\
\text { debt }\end{array}$ & $\begin{array}{c}\text { Stress from } \\
\text { debt collection }\end{array}$ \\
\hline $\begin{array}{c}\text { Insurance money } \\
\text { from suicide }\end{array}$ & $0.678^{*}$ & $0.695^{*}$ & 0.485 & -0.025 & 0.243 & $0.812^{* *}$ & $0.837^{* *}$ & $0.778^{*}$ & $0.937^{* *}$ \\
$p$ & 0.045 & 0.038 & 0.185 & 0.949 & 0.529 & 0.008 & 0.005 & 0.014 & 0.000 \\
\hline
\end{tabular}

Spearman's rank-correlation coefficient. Note. ${ }^{*} p<0.05,{ }^{* *} p<0.001$.

Suicide for gaining insurance payouts was correlated with the following other factors in males: bankruptcy, business slump, multiple debts, joint guarantee debt, other debt, and stress from debt collection. For example, if a man fails in his business, his company goes bankrupt, or debts pile up, he may choose death by suicide in order to gain insurance payouts and fulfill his obligations. Thus, suicide in Japanese males is substantially influenced by economic conditions [14]. For Japanese males, work is an important concern, and there is a high value placed on working [15]. Moreover, when they are under psychological stress due to economic issues, their outlook toward life may become narrow and pessimistic. They may take economic issues seriously to the extent that they choose to die in order to deal with them.

There are several approaches that may help prevent these suicides. First, it is important to promote help seeking by these people, as help-seeking behaviors reduce the risk of suicide [16] [17]. As previous studies show, among the Japanese experiencing suicidal ideation, $73.9 \%$ did not seek help, and among those who have attempted suicide, $51.1 \%$ did not seek help [18]. For people who think about committing suicide to gain insurance payouts, it will be necessary to consult someone who can solve their economic issues; as this implies, access to and dissemination of debt and financial counseling services needs to be increased. Awareness campaigns promoting help seeking are important too. In addition, persons who are under extreme stress due to economic issues are at risk for developing mental illnesses such as depression. Indeed, in Japan, the most common factor influencing suicide is health problems, including mental illness [19]; thus, people experiencing mental illness should receive treatment, and for early treatment and prevention, it is important to disseminate correct knowledge about mental illness to society. Finally, one study reported that the suicide ratio decreased with the extension of the suicide-exempted period by insurers [20]; thus, the structure of insurance policies and eligibility may also help reduce suicide committed in order to access payouts. For people who consider committing suicide in order to gain insurance payouts, being unable to obtain insurance money by doing so will prevent them from achieving this objective. The extension of the suicide-exempted period may be effective to reduce at least this motive for suicide.

One thing that we must add here, for several reasons, is that it is unlikely that taking out a life insurance policy is directly linked to the risk of suicide. The rate 
of participation in life insurance schemes among people who have attempted suicide is lower than that in the general population in Japan [21]. This may be because people who have attempted suicide are viewed as likely to be mentally ill [18], which may make it difficult for them to buy life insurance. Moreover, mentally ill people are poorer on average than the general population, which may also present a difficulty. Unemployed persons are common among suicides in Japan-59.6\% in 2014 [3] —and it appears that their participation rate in life insurance may be lower than that of the general population. Shirouzu reported that the suicide mortality ratio is lower among insured people than among the general population [22]; in contrast, however, Choi et al. reported that the suicide rate is positively correlated with life insurance premium per capita in OECD countries [23]. Several previous studies show that the suicide mortality ratio of Japanese people with life insurance contracts worth at least 50 million yen (about 450,000 US dollars) is higher than that of people without such contracts [20] [24]. Thus, large death benefits may be linked to motivation for suicide. Perhaps suicide for gaining insurance payouts is complexly intertwined with various factors; certainly, it has not been analyzed sufficiently by this study or by previous studies, and additional work is required to develop more effective preventive measures.

\section{Conclusion}

Our findings on suicide committed for the purpose of gaining insurance payouts in Japan show that the risk is higher among men than among women and higher among people in their 40s through 60s than in other age groups, and it is likely to be associated with debt. Important actions to prevent this kind of suicide will include promoting help seeking, further dissemination of debt counseling and financial counseling services, and extended treatment for mental illness. However, further studies, such as psychological autopsy, which establish the background of suicide for gaining insurance payouts, are required in order to develop more effective preventive measures.

\section{Conflict of Interest}

The authors have no conflicts of interest to state for the present manuscript.

\section{Role of Funding Source}

This study was supported by the Japan Society for the Promotion of Science (KAKENHI grant 16K12241).

\section{References}

[1] World Health Organization (2014) Preventing Suicide: A Global Imperative. World Health Organization, Geneva.

[2] Organisation for Economic Co-operation and Development. Health Statistics 2016-Frequently Requested Data. 
http://www.oecd.org/els/health-systems/OECD-Health-Statistics-2016-FrequentlyRequested-Data.xls

[3] Cabinet Office (Japan) (2015) Outline of Suicide and Implementation Status of Suicide Prevention in Japan 2014 (Summary).

http://warp.da.ndl.go.jp/info:ndljp/pid/9929094/www8.cao.go.jp/jisatsutaisaku//whi tepaper/en/w-2015/pdf/chap1-1.pdf

[4] National Police Agency (Japan) (2007) Summary Document Concerned with Suicide in 2007. (In Japanese)

https://www.npa.go.jp/safetylife/seianki/jisatsu/H19/H19_jisatunogaiyou.pdf

[5] National Police Agency (Japan) (2008) Summary Document Concerned with Suicide in 2008. (In Japanese) https://www.npa.go.jp/safetylife/seianki/jisatsu/H20/H20_jisatunogaiyou.pdf

[6] National Police Agency (Japan) (2009) Summary Document Concerned with Suicide in 2009. (In Japanese) https://www.npa.go.jp/safetylife/seianki/jisatsu/H21/H21_jisatunogaiyou.pdf

[7] National Police Agency (Japan) (2010) Summary Document Concerned with Suicide in 2010. (In Japanese)

https://www.npa.go.jp/safetylife/seianki/jisatsu/H22/H22_jisatunogaiyou.pdf

[8] Phillips, M.R., Shen, Q., Liu, X., Pritzker, S., Streiner, D., Conner, K. and Yang, G. (2007) Assessing Depressive Symptoms in Persons Who Die of Suicide in Mainland China. Journal of Affective Disorders, 98, 73-82. https://doi.org/10.1016/j.jad.2006.07.020

[9] Centre for Suicide Research and Prevention (2005) Research Findings into Suicide and Its Prevention-Final Report 2005 July. University of Hong Kong, Hong Kong.

[10] Matsumoto, T., Matsushita, S., Okudaira, K., Naruse, N., Cho, T., Muto, T., Ashizawa, T., Konuma, K., Morita, N. and Ino, A. (2012) Sex Differences in Risk Factors for Suicidality among Japanese Substance Use Disorder Patients: Association with Age, Types of Abused Substances, and Depression. Psychiatry and Clinical Neurosciences, 66, 390-396. https://doi.org/10.1111/j.1440-1819.2012.02374.x

[11] Suominen, K., Isometsä, E., Haukka, J. and Lönnqvist, J. (2004) Substance Use and Male Gender as Risk Factors for Deaths and Suicide. Social Psychiatry and Psychiatric Epidemiology, 39, 720-724. https://doi.org/10.1007/s00127-004-0796-7

[12] Japan Institute of Life Insurance (2015) National Survey of Life Insurance: Results of the Survey. (In Japanese) http://www.jili.or.jp/research/report/xls/h27zenkoku/1-11.xlsx

[13] Japan Institute of Life Insurance (2016) Survey on Life Security 2016. (In Japanese) http://www.jili.or.jp/research/report/xls/h28hosho/4-6.xlsx

[14] Liu, Y., Zhang, Y., Cho, Y.T., Obayashi, Y., Arai, A. and Tamashiro, H. (2013) Gender Differences of Suicide in Japan, 1947-2010. Journal of Affective Disorders, 151, 325-330. https://doi.org/10.1016/j.jad.2013.05.100

[15] Cabinet Office (Japan). (2012) Outline of Awareness Survey Report on "Gender Equality for Men". (In Japanese) http://www.gender.go.jp/research/kenkyu/dansei_ishiki/pdf/gaiyou.pdf

[16] Moskos, M., Olson, L., Halbern, S., Keller, T. and Gray, D. (2007) Utah, Youth Suicide Study: Barriers to Mental Health Treatment for Adolescents. Suicide and LifeThreatening Behaviors, 37, 179-186. https://doi.org/10.1521/suli.2007.37.2.179

[17] Owens, C., Lambert, H., Donovan, J. and Lloyd, K.R. (2005) A Qualitative Study of Help Seeking and Primary Care Consultation Prior to Suicide. British Journal of General Practice, 55, 503-509. 
[18] Nippon Foundation (2017) Nippon Foundation Suicide Awareness Survey 2016. (In Japanese)

http://www.nippon-foundation.or.jp/what/projects/suicide_measures/img/3.pdf

[19] Cabinet Office (Japan) (2015) Outline of Suicide and Implementation Status of Suicide Pprevention in Japan 2014 (Summary) Section 2: Special Issue. (In Japanese) http://warp.da.ndl.go.jp/info:ndljp/pid/9929094/www8.cao.go.jp/jisatsutaisaku//whi tepaper/en/w-2015/pdf/chap1-2.pdf

[20] Shirouzu, T. (2011) Suicide and Life Insurance in These Days. Journal of the Association of Life Insurance Medicine Japan, 109, 102-119. (In Japanese)

[21] Iwasaki, Y. and Kurosawa, H. (1990) Insurance Contract State of Suicide Attempts. Journal of the Association of Life Insurance Medicine Japan, 88, 275-279. (In Japanese)

[22] Cho, S.-E., Na, K.-S., Cho, S.-J., Im, J.-S. and Kang, S.-G. (2015) Geographical and Temporal Variations in the Prevalence of Mental Disorders in Suicide: Systematic Review and Meta-Analysis. Journal of Affective Disorders, 190, 704-713. https://doi.org/10.1016/j.jad.2015.11.008

[23] Choi, Y.J., Chen, J. and Sawada, Y. (2015) Life Insurance and Suicide: Asymmetric Information Revisited. BE Journal of Economic Analysis and Policy, 15, 1127-1149. https://doi.org/10.1515/bejeap-2014-0081

[24] Yamamoto, T. (1988) Mortality Status of Standard Risk Engaged in Expensive Contracts in Our Company. Journal of the Association of Life Insurance Medicine Japan, 85, 197-203. (In Japanese) 